
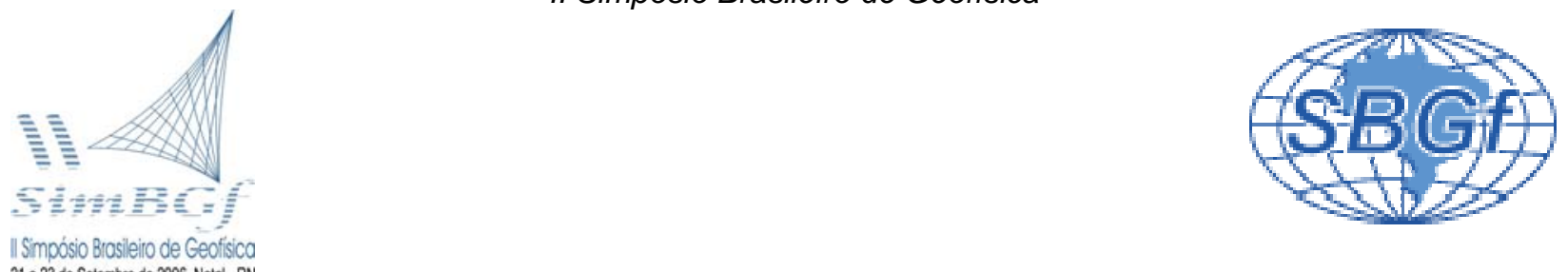

,21 a 23 de Setembro de 2006, Natal - RN

\title{
Inversão sísmica tomográfica usando traçado analítico de raios
}

Vânia G. de Brito dos Santos \& Wilson M. Figueiró, CPGG, LAGEP, IGEO, Universidade Federal da Bahia, Salvador, Brasil

Copyright 2006, SBGf - Sociedade Brasileira de Geofísica

Este texto foi preparado para a apresentação no II Simpósio de Geofísica da Sociedade Brasileira de Geofísica, Natal, 21-23 de setembro de 2006. Seu conteúdo foi revisado pela Comissão Tecno-científica do II SimBGf mas não necessariamente representa a opinião da SBGf ou de seus associados. E proibida a reprodução total ou parcial deste material para propósitos comerciais sem prévia autorização da SBGf.

\section{Resumo}

Traçamento analítico de raios sísmicos é realizado em modelo de campo de velocidades compressionais, cujo quadrado da vagarosidade é parametrizado por uma função polinomial usual. Tal modelo pode ser usado como modelo de referência para o tratamento de modelos mais complicados e, além disso, permite que o problema de conexão de dois pontos do modelo, por um traçado de raio, seja resolvido de modo analítico, isto é: dados a posição da fonte e do receptor, é possível obterse, de modo analítico, o ângulo de partida da trajetória do raio da fonte, a fim de que o raio chegue exatamente à posição do receptor. Em seguida, utiliza-se como dados sintéticos, tempos de trânsito calculados ao longo das trajetórias obtidas. Isto permite, a utilização do método de Gauss-Newton em experimento de inversão tomográfica. Como resultado, um modelo invertido muito próximo do alvo é obtido, partindo-se de modelo inicial não muito próximo do modelo alvo.

\section{Introdução}

Em sísmica, os métodos de inversão tomográfica têm por objetivo estimar parâmetros que sejam capazes de representar estruturas geológicas de sub-superfície usando traçamento de raios sísmicos que, de diferentes modos, atravessam tais estruturas. Com isto, espera-se, ao final, poder visualizar imagens que sejam, mesmo que de modo aproximativo, uma expressão de uma configuração geológica não acessível à observação direta. Dito de outro modo, trata-se de obter um modelo sísmico-geológico que justifique adequadamente 0 conjunto de dados observados. O traçamento de raios sísmicos nos permite calcular dados sintéticos, como, por exemplo, o tempo de trânsito da onda em sua viagem da fonte ao receptor ao longo da trajetória do raio. Assim, uma vez obtida tal trajetória, o tempo de trânsito é sobre ela calculado. A solução do problema de traçar raios conectando dois pontos de um modelo de velocidades sísmicas apóia-se na teoria do raio (Popov, 2002). Dispondo-se de dados reais ou sintéticos e de um método para o cálculo dos dados em modelos conhecidos, pode-se implementar um procedimento de inversão tal como o método de Gauss-Newton (Bishop et al., 1985; e Figueiró, 1994). As ondas sísmicas são geradas em fontes, propagam-se através de um meio geológico, são refletidas em interfaces, e registradas em receptores, localizados na superfície de observação, nos quais a onda deixa registrada as influências por ela sofrida ao atravessar o meio geológico. Apesar do raio não gozar do mesmo "status" de existência física conferido à onda, nada nos impede de traçar, segundo as equações do raio, linhas conectando fontes e receptores, que, mesmo não possuindo um caráter físico tão natural quanto a onda, pode-se sobre elas obter, dentre outras propriedades da onda, os seus tempos de trânsito ("traveltime"). Um método para a obtenção de solução para o problema de conexão de dois pontos de um meio por um raio é uma técnica conhecida como Método Paraxial (Figueiró \& Madariaga, 2000). O modelo aqui estudado é bidimensional, heterogêneo, e isotrópico. Os raios estão representando trajetórias de propagações ondulatórias compressionais.

\section{Metodologia de Traçado de Raio}

As equações do raio são obtidas através da aplicação do princípio de Fermat ao seguinte funcional:

$$
t(C)=\int_{C} \frac{d s}{V},
$$

onde $C$ é um caminho que conecta dois pontos do modelo, $t$ é o tempo de trânsito da onda ao longo de $C$, $V=V(x, z)$ é a velocidade da onda no meio representado pelo modelo, e ds é o elemento de comprimento de arco da curva $C$. Isto leva ao seguinte sistema de equações (Červený, 1987):

$$
\left\{\begin{array}{c}
\frac{d \vec{X}(\tau)}{d \tau}=\vec{P}(\tau) \\
\frac{d \vec{P}(\tau)}{d \tau}=\frac{1}{2} \vec{\nabla}\left[\frac{1}{V^{2}}\right] .
\end{array}\right.
$$

O modelo de campo de velocidade tratado é:

$$
V(x, z)=\frac{1}{\sqrt{a+b x+c z}} .
$$

Derivando a primeira equação de (2) em relação a $\tau$ obtêm-se:

$$
\frac{d^{2} \vec{X}(\tau)}{d \tau^{2}}=\frac{d \vec{P}(\tau)}{d \tau}
$$


A equação (4) juntamente com a segunda de (2) permite escrever a seguinte equação:

$$
\frac{d^{2} \vec{X}(\tau)}{d \tau^{2}}=\frac{1}{2} \vec{\nabla}\left[\frac{1}{V^{2}(x, z)}\right] .
$$

Daí obtêm-se:

$$
\frac{d^{2} x(\tau)}{d \tau^{2}}=\frac{b}{2} \text { e } \frac{d^{2} z(\tau)}{d \tau^{2}}=\frac{c}{2} .
$$

Resolvendo as equações (6) e utilizando as condições iniciais do problema: posição de fonte $\vec{S}=(0,0)$, do receptor $\vec{R}=(R, 0)$, e vetor vagarosidade na fonte $\vec{P}(0)=\left(P_{x}(0), P_{z}(0)\right)$, chega-se às equações:

$$
\left\{\begin{array}{l}
R=\frac{b}{4} \tau_{R}^{2}+P_{x}(0) \tau_{R} \\
0=\frac{c}{4} \tau_{R}^{2}+P_{z}(0) \tau_{R}
\end{array}\right.
$$

onde $\tau_{R}$ é o parâmetro da trajetória do raio na posição $\vec{R}$. Daí, utiliza-se o Hamiltoniano, que sobre o raio é igual a 0 . Por fim, fazendo as substituições devidas chega-se a uma equação biquadrada que, sendo resolvida, fornece $\tau_{R}$, que permite determinar $P_{x}(0)$ e $P_{z}(0)$, que fornecem a direção de saída que o raio deve ter para atingir a posição do receptor. Assim, pode-se traçar o raio analiticamente. De posse do raio, é possível determinar o tempo de percurso sobre a trajetória analítica do raio. Para o modelo considerado, supondo que não se tem reflexões nas interfaces, é possível encontrar uma expressão analítica para o tempo de percurso do raio, utilizando-se a seguinte equação:

$$
\frac{d T}{d \tau}=\frac{1}{V^{2}} .
$$

Donde obtêm-se:

$$
d T=(a+b x+c z) d \tau .
$$

Então, o tempo de percurso do raio entre fonte e receptor é dado por:

$$
T=\int_{0}^{\tau_{R}}\left\{a+\left[b \cdot P_{x}(0)+c \cdot P_{z}(0)\right] \cdot \tau+\frac{\left(b^{2}+c^{2}\right)}{4} \cdot \tau^{2}\right\} d \tau .
$$

Resolvendo a integral tem-se:

$$
T=\frac{\left(b^{2}+c^{2}\right)}{12} \cdot \tau_{R}^{3}+\frac{\left[b \cdot P_{x}(0)+c \cdot P_{z}(0)\right]}{2} \cdot \tau_{R}^{2}+a \cdot \tau_{R} .
$$

Com a expressão (11), calcula-se, analiticamente, o tempo de percurso do raio entre a fonte e o receptor.

\section{Definição do Modelo}

Realiza-se o trabalho com o modelo bidimensional descrito pela equação (3) com as seguintes dimensões: $9,0 \mathrm{~km}$ de extensão horizontal e $3,0 \mathrm{~km}$ de profundidade. Inicialmente faz-se uma modelagem com parâmetros para uma faixa de variação de velocidade de $1,0 \mathrm{~km} / \mathrm{s}$ à $8,0 \mathrm{~km} / \mathrm{s}$ porém encontra-se dificuldades para obtenção de coeficientes do polinômio tais que permitam um traçamento estável de raios. Assim, altera-se o intervalo de variação de velocidade para $[0,88 ; 4,0] \mathrm{km} / \mathrm{s}$ o que ocasionou uma significativa melhora na estabilidade do traçado dos raios. Obteve-se, então, um campo de velocidade polinomial com os seguintes coeficientes: $a=1,3 \mathrm{~s}^{2} \mathrm{~km}^{-2} ; \quad b=-0,1 \mathrm{~s}^{2} \mathrm{~km}^{-3} ;$ e $c=-0,1125 \mathrm{~s}^{2} \mathrm{~km}^{-3}$. Sua imagem gráfica está representada pela Figura 1.

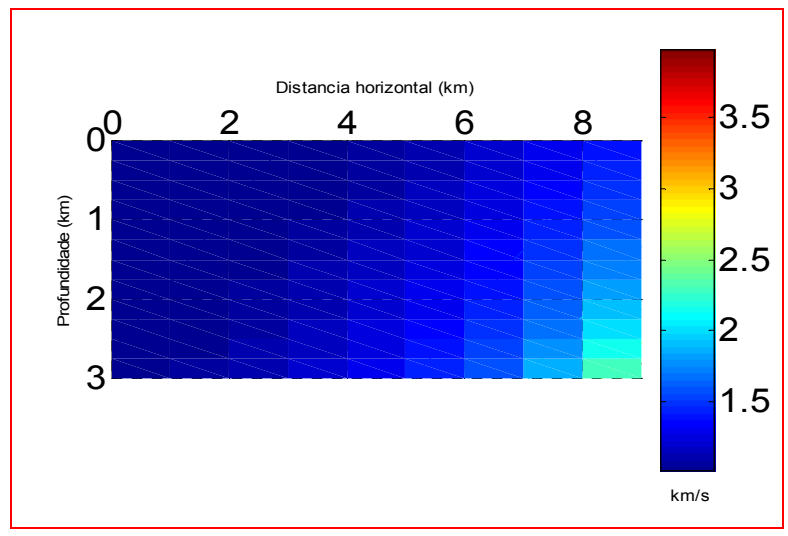

Figura 1: Campo de Velocidade da forma dada por (3) com valores para $a, b$, e $c$; dados na seção Definição do Modelo.

Percebe-se que ocorre uma brusca variação de velocidade na região do campo compreendida entre as profundidades de 2,0 e $3,0 \mathrm{~km}$ e os afastamentos horizontais situados entre 7,0 e $9,0 \mathrm{~km}$ (canto direito inferior do campo). Isto é uma característica geral do modelo. Embora, para efeito de resolução do problema, a interpretação geológica do modelo seja irrelevante, podese dizer que ele pode ser visto como sendo uma região compreendida e lateralmente comprimida entre o topo esquerdo de um domo salino e a superfície. É construído um algoritmo para o traçado de raios e cálculo do tempo de trânsito. Foram obtidos, assim, os tempos referentes ao modelo alvo. Em seguida, é construído um algoritmo para a Inversão de dados (tempos de trânsito) usando o método de Gauss-Newton.

\section{Resultados}

A posição da fonte $\vec{S}$ foi mantida na superfície de observação, $z=0$, com $x_{S}=0,0 \mathrm{~km}$. Quanto às posições $\vec{R}$ dos receptores, elas totalizam 18 e estão distribuídas 
ao longo da superfície de observação segundo a fórmula $R_{i}=0,5 . i \mathrm{~km}, i \in\{1,2,3, \cdots, 18\}$.

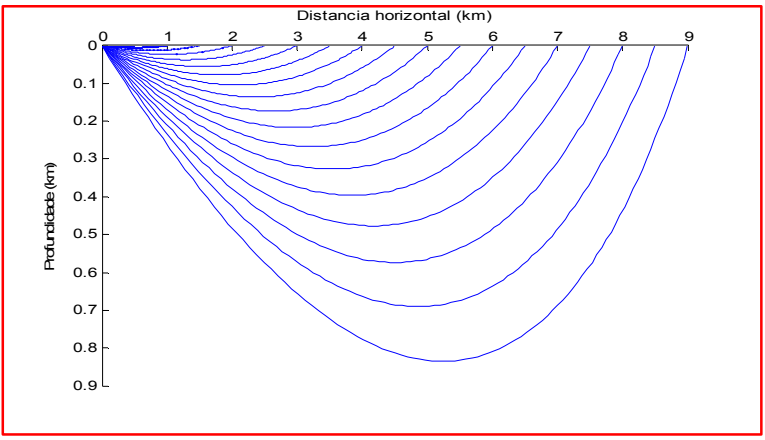

Figura 2: Disposição no modelo dos raios traçados que conectam fonte a receptores.

Pode-se observar que o problema do ponto de retorno foi amenizado, porém o raio mais profundo ainda não atinge $50 \%$ da profundidade máxima do modelo. Pode-se supor que com o aumento da extensão consegue-se raios mais profundos, para tanto seria necessário determinar novos parâmetros para esse suposto limite horizontal máximo. Os tempos calculados neste modelo foram computados pela equação (11).

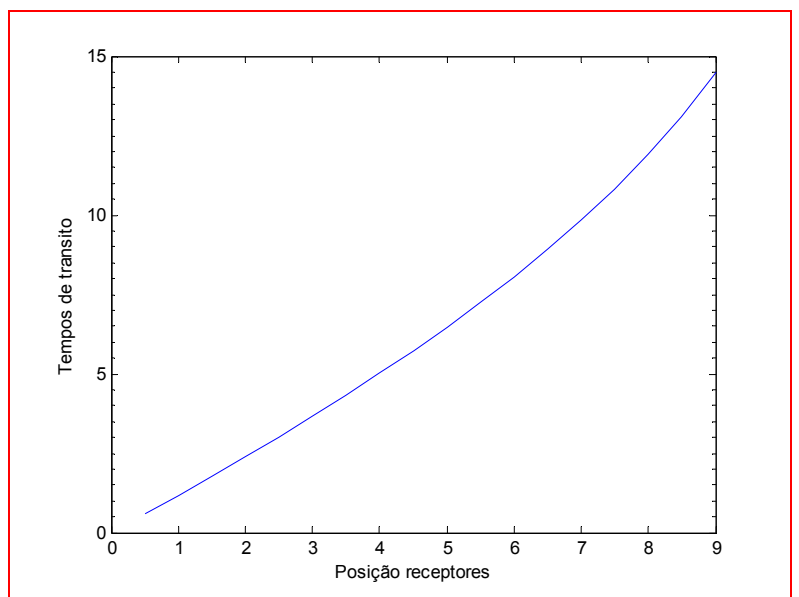

Figura 3: Tempos de Trânsito. O eixo horizontal é dado em $\mathrm{km}$ e o vertical em $S$.

A Figura 3 mostra a curva dos tempos de chegada dos raios nos receptores distribuídos ao longo da superfície de observação. Para alguns modelos, ao realizar-se a modelagem dos dados, percebe-se que, para alguns receptores, surgem tempos complexos, isto ocorre devido às restrições da abordagem analítica, que contém expressões envolvendo raízes quadradas, quando algumas regiões do modelo não são perturbadas pela propagação ondulatória. Entretanto, essa restrição não impediu a obtenção de bons resultados. Analisando as diferenças entre os modelos inicial e alvo e entre os modelos invertido e alvo, conseguiu-se obter um resultado regular: uma diferença de $26,51 \%$ entre os modelos inicial e alvo, correspondeu a uma diferença de $5,5 \%$ entre os modelos invertido e alvo. O método foi testado em presença de ruído, e apresentou os seguintes resultados: com relação sinal-ruído de 0,4 (40\%), o programa é interrompido, devido as indeterminações que surgem no cálculo dos tempos de trânsito; com 0,2 (20\%) de ruído, o método converge em 8 iterações, atingindo um erro de $7 \%$; e sem ruído a convergência se deu em 5 iterações, atingindo um erro de 4,6\%. Os cálculos do tempo de trânsito também foram realizados numericamente e foram determinados valores bem próximos daqueles obtidos analiticamente.

\section{Discussões e Conclusões}

O estudo de modelos que admitem uma abordagem analítica na modelagem (por exemplo: obtenção dos tempos de trânsito) e, também, na obtenção de derivadas parciais dos dados relativamente aos parâmetros do modelo, é interessante, pois tais modelos podem ser usados como modelos de referência em trabalhos de inversão que considerem modelos mais complicados. Além disso, em tomografia, eles possibilitam uma solução extremamente econômica, em termos de processamento computacional, para o problema de conexão fontereceptor ("two-points ray tracing problem"). Entretanto, a abordagem analítica exige habilidades matemáticas e de programação necessárias para contornar problemas tais como o aparecimento de tempos complexos. Nos experimentos realizados verificou-se um tempo de processamento bastante pequeno. Uma dificuldade encontrada com o modelo usado neste trabalho foi a da instabilidade relativa ao seu realismo sísmico, isto é: pequenas perturbações dos parâmetros podem fazer com que apareçam velocidades exageradamente altas, o que, erroneamente, pode ser interpretado como uma limitação do método de Gauss-Newton, que, como é sabido, tem algumas restrições quanto a amplitude de seu domínio de convergência. Entretanto, os resultados obtidos neste trabalho, com e sem ruído, evidenciou uma boa estabilidade. A acurácia (Figura 4), evidenciada ao analisar-se uma comparação das diferenças entre os modelos inicial e alvo e entre os modelos invertido e alvo, foi satisfatória. Acredita-se que a abordagem utilizada neste trabalho possa ser útil para estudo de campos de velocidade parametrizados por expressões semelhantes, isto é: parametrizações que envolvem termos quadráticos e cruzados em expressões polinomiais.

\section{Agradecimentos}

Ao CPGG-UFBA pelas condições de trabalho disponíveis no Laboratório de Geofísica. 


\section{Referências}

Červený, V., 1987. Ray Method for Three-Dimensional Seismic Modeling. Petroleum Industry Course, The Norwegian Institute of Technology.

Bishop, T.N., Bube, K.P., Cutler, R.T., Langan, R.T., Love, P.L., Resnick, J.R., Shuey, R.T., Spindler, D.A., \& Wyld, H.W., 1985. Tomographic determination of velocity and depth in laterally varyng media. Geophysics, 50: 903923.

Figueiró, W.M., 1994. Tomografia de Reflexão no caso de Refletor Curvo. Tese de Doutorado, PPPG-UFBA, Salvador.
Figueiró, W.M., 2000. Seismic Ray-tracing and Estimate of Geological Model Parameters. Research Report, Agreement of Thecnical and Scientific Cooperation PSGCPGG-UFBA.

Figueiró, W.M., \& Madariaga, R.I., 2000. A method to avoid caustic arrival points. Expanded Abstracts of the $70^{\text {th }}$ SEG Meeting, Calgary, Canada.

Menke, W., 1989. Geophysical Data Analysis: Discrete Inverse Theory. Academic Press, New York, USA.

Popov, M.M., 2002. Ray Theory and Gaussian Beam Method for Geophysicists. EDUFBA, Salvador, Brazil.

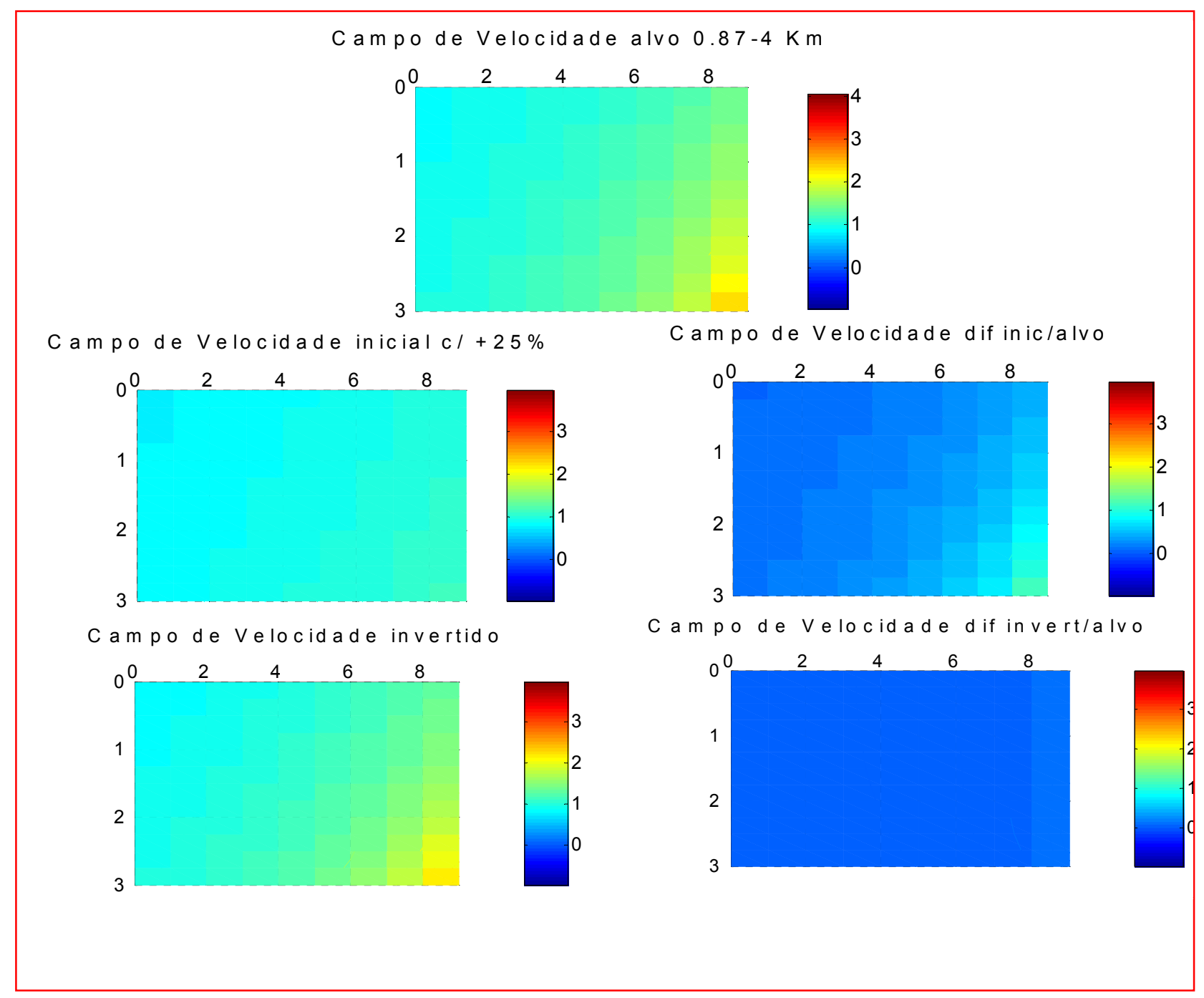

Figura 4: Campos de velocidade (pela ordem: modelo alvo, modelo inicial, diferença entre os modelos inicial e alvo, modelo invertido, e diferença entre os modelos invertido e alvo). 